\title{
Mission results from the first GEOSTAR observatory (Adriatic Sea, 1998)
}

\author{
Laura Beranzoli ${ }^{1}$, Thomas Braun ${ }^{1}$, Massimo Calcara ${ }^{1}$, Paolo Casale ${ }^{1}$, Angelo De Santis ${ }^{1,4}$, Giuseppe D’Anna ${ }^{1}$, \\ Domenico Di Mauro $^{1}$, Giuseppe Etiope ${ }^{1}$, Paolo Favali ${ }^{1,4}$, Jean-Luc Fuda ${ }^{2}$, Francesco Frugoni ${ }^{1}$, \\ Fabiano Gamberi $^{3}$, Michael Marani ${ }^{3}$, Claude Millot ${ }^{2}$, Caterina Montuori $^{1}$, \\ and Giuseppe Smriglio ${ }^{1 \dagger *}$ \\ ${ }^{1}$ Istituto Nazionale di Geofisica e Vulcanologia (INGV), Roma, Italy \\ ${ }^{2}$ Laboratoire d'Océanographie et de Biogeochemie-CNRS, Marseille, France \\ ${ }^{3}$ Istituto per la Geologia Marina-CNR, Bologna, Italy \\ ${ }^{4}$ Università “G. D'Annunzio”, Chieti, Italy
}

(Received May 30, 2002; Revised August 8, 2003; Accepted August 8, 2003)

\begin{abstract}
We assess the first mission of the GEOSTAR (GEophysical and Oceanographic STation for Abyssal Research) deep-sea multidisciplinary observatory for its technical capacity, performance and quality of recorded data. The functioning of the system was verified by analyzing oceanographic, seismological and geomagnetic measurements. Despite the mission's short duration (21 days), its data demonstrated the observatory's technological reliability and scientific value. After analyzing the oceanographic data, we found two different regimes of seawater circulation and a sharp and deepening pycnocline, linked to a down-welling phenomenon. The reliability of the magnetic and seismological measurements was evaluated by comparison with those made using on-land sensors. Such comparison of magnetic signals recorded by permanent land geomagnetic stations and GEOSTAR during a "quiet" day and one with a magnetic storm confirmed the correct functioning of the sensor and allowed us to estimate the seafloor observatory's orientation. The magnitudes of regional seismic events recorded by our GEOSTAR seismometer agreed with those computed from land stations. GEOSTAR has thus proven itself reliable for integrating other deep-sea observation systems, such as modular observatories, arrays, and instrumented submarine cables.
\end{abstract}

Key words: Benthic observatories, oceanographic, seismological and magnetic data.

\section{Introduction}

Recent studies of the Earth's oceans, atmosphere, geosphere and biosphere have clarified that no component of such natural systems is really isolated, and more realism is necessary to understand the complex interrelationships among natural phenomena. For example, geological and biological systems are strongly linked, as evident in certain underwater volcanic environments where geothermal, not solar, energy powers the thriving ecosystem (http: / / www . deos.org). Improving the distribution of scientific multidisciplinary observatories - especially inadequate in the oceans - will help us investigate the Earth's structure and dynamics. In particular, global efforts to settle monitoring systems on the sea bottom have been made since the early '90s (e.g., Kasahara et al., 1995; Montagner and Lancelot, 1995; Butler et al., 2000).

Short-term experiments are mainly concerned with a single discipline, such as the seismological experiments French Pilot OFM-SISMOBS (Montagner et al., 1994a, b), SISBALIG II OBS array (Campillo et al., 1995), and MOISE (Romanowicz et al., 1998). By contrast, long-term and realtime experiments are generally multidisciplinary and innova-

\footnotetext{
$\dagger$ Prematurely deceased in 2001
}

Copy right(C) The Society of Geomagnetism and Earth, Planetary and Space Sciences (SGEPSS); The Seismological Society of Japan; The Volcanological Society of Japan; The Geodetic Society of Japan; The Japanese Society for Planetary Sciences. tive in implementing new technology for power supply and real-time data transmission.

In 1993, a seafloor observatory was deployed off Hatsushima Island by the Japan Marine Science and Technology Centre (JAMSTEC) to study how biological, seismic, and volcanic activities relate along the plate boundaries (Momma et al., 1995). Re-used submarine cables for power supply and data transmission are the base of the VENUS project and the GeO-TOC program which are devoted to the permanent installation on the seafloor of sensors for geophysical measurements (Kasahara and Momma, 1995; Kasahara et al., 1998, 2000). The Hawaii Undersea Geo-Observatory Project (HUGO), installed in 1997, was aimed at the integration of marine electro-optical cables with existing sensor technologies to create a permanent multidisciplinary laboratory on the ocean floor at the top of the Loihi submarine active volcano (Dunnebier, 1995). HUGO has the potential of supporting experiments from many disciplines, including volcanology, biology and geochemistry. Unfortunately after 6 months from the installation, the main HUGO cable developed a short circuit to sea water and a new cable must be obtained and installed (Duennebier et al., 2002). Despite the failure, this experiment accomplished several important tasks among which the transmission of high rate, high-fidelity data from the summit of Lahoi. In mid 1998 the Hawaii-2 Observatory (H2O) was installed on a retired commercial submarine telephone cable (Chave et al., 2002; 


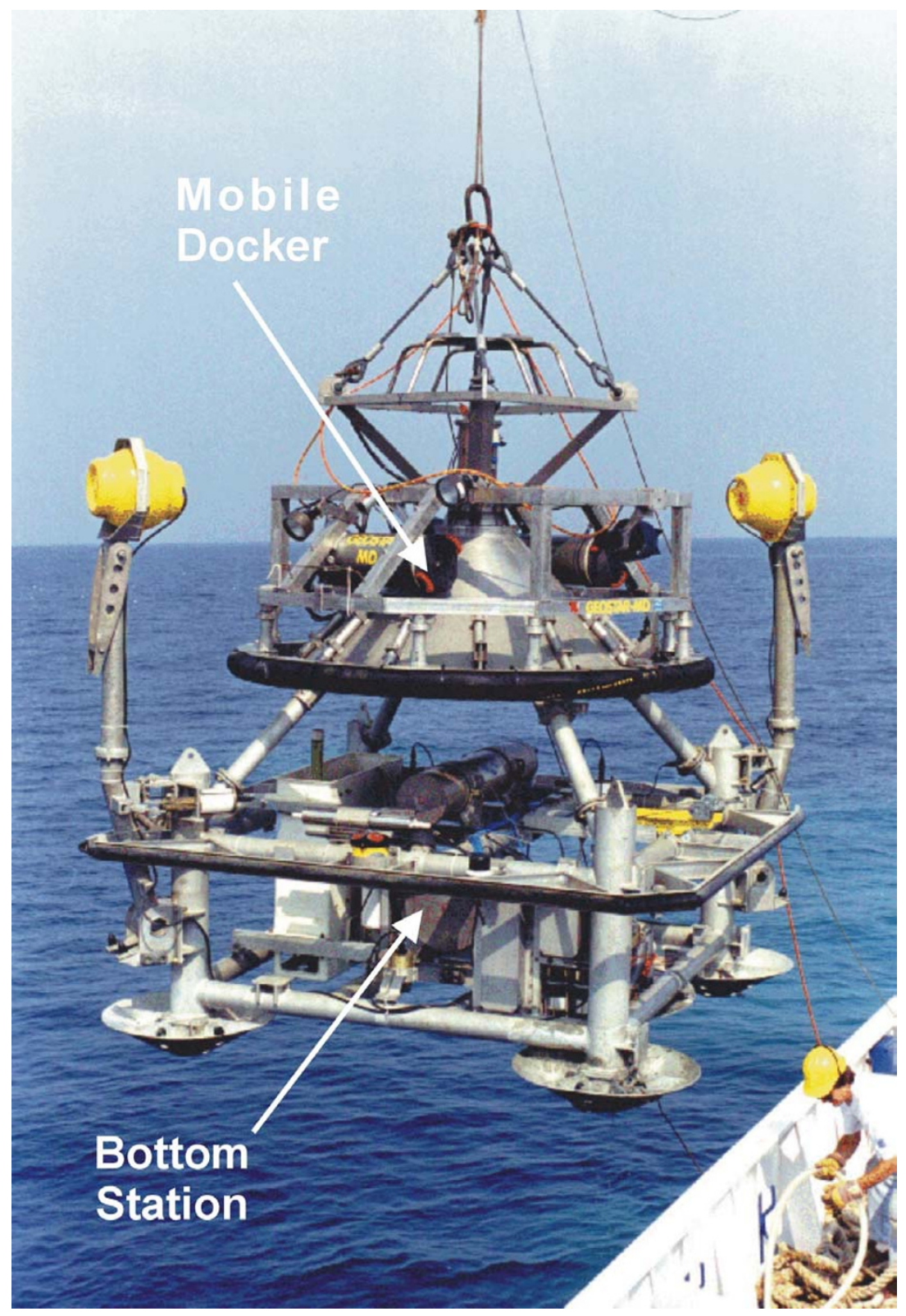

Fig. 1. The complete GEOSTAR system during the recovery by means of the R/V Urania at the end of the shallow water mission in the Adriatic Sea. The deployment/recovery module (Mobile Docker) has performed the recovery and is already connected to the Bottom Station.

Petitt et al., 2002). It consists of a cable termination and a junction box in $5000 \mathrm{~m}$ of water placed half way between California and Hawaii. Instruments may be connected by a Remote Operated Vehicle (ROV) to the junction box.

Most of the above mentioned experiments need ROVs, not only to deploy and connect devices and sensor packages to cable terminations, but also to correctly install and operate the sensors.

In the late '90s experiments aimed at the monitoring of coastal processes have developed underwater observatories with real-time data for rapid environmental assessment and physical/biological forecasting in coastal waters. To this end, observational data are collected also from satellites, aircrafts, ships, cabled instrumented nodes, fixed/relocatable moorings, and autonomous underwater vehicles providing continuous access to the coastal and open oceans (e.g., Schofield et al., 2002; Austin et al., 2002).
Under the Marine Science and Technology (MAST) Program of the European Commission (EC), feasibility studies begun in the early '90s have established the basic technologies needed for a prototype, deep-sea multidisciplinary observatory better than traditional free-lander modules. Of special interest were DESIBEL (Deep-sea intervention on future benthic laboratory) and ABEL (Abyssal Benthic Laboratory) feasibility studies (Thiel et al., 1994; Berta et al., 1995; Rigaud et al., 1998). Between 1995 and 1999 the EC funded the GEOSTAR project to design and develop an autonomous deep-sea observatory (hereafter referred to as GEOSTAR) for multidisciplinary, long-term monitoring (up to 1 year). GEOSTAR would operate down to $4000 \mathrm{~m}$ and transmit data in near-real-time. The observatory was to comprise a wide range of sensors and serve as a facility for external experiments, representing a prototype, central node for submarine monitoring networks. 


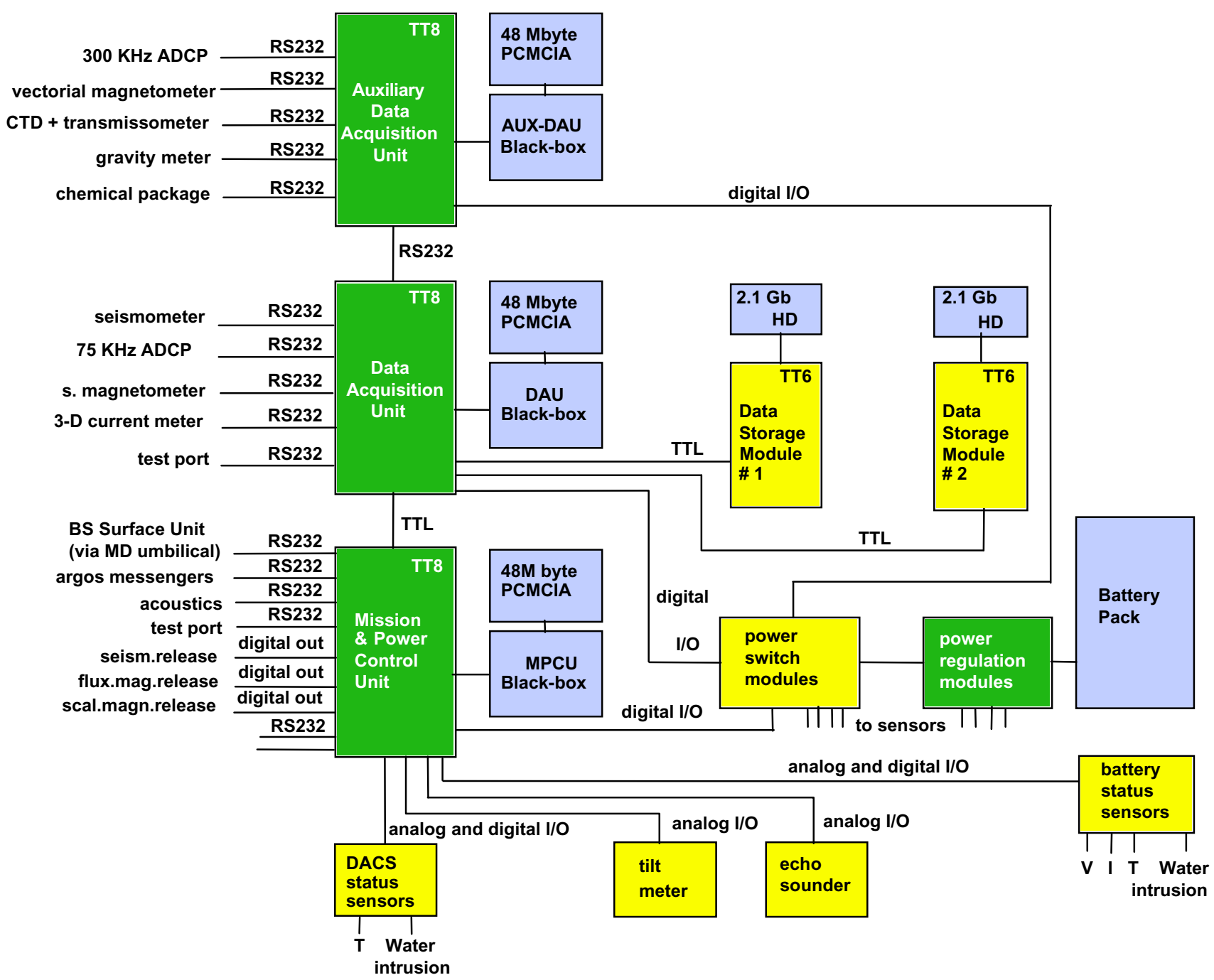

Fig. 2. GEOSTAR DACS architecture. The green boxes represent the 'heart' of the DACS: the Data Acquisition Unit and the Auxiliary Data Unit manage the data acquired by the sensor packages connected via RS232 links. The Mission Power and Control Unit has the task to manage the connection to the Mobile Docker through an umbilical, to activate the devices for the release of some of the sensor packages (seismometer and magnetometers), to manage the data flow and the release of the data capsules and to operate the acoustic communication link. The yellow boxes are status devices checking the correct operation and the integrity of the BS. The violet boxes are service devices, namely batteries and mass-memory.

The most innovative features of GEOSTAR are both technological and scientific. Deployment and recovery operations are ship-handled and performed through a dedicated tool: the Mobile Docker, tethered by an opto-electromechanical cable and maneuverable from a medium-size research vessel. One communication system on the observatory stores the acquired measurements in capsules automatically launched to the sea surface. These transmit data via satellite. A unique time reference for all GEOSTAR's measurements allows a quick and reliable comparison among the observatory data.

This paper deals with the results of the GEOSTAR observatory's first mission in shallow waters (around $40 \mathrm{~m}$ w.d.) of the Adriatic Sea in 1998. It lasted 21 days and was successfully completed. Through the GEOSTAR-2 project, the EC funded an enhancement phase from 1999-2001 to carryout the first long-term deep-sea mission. This mission was successful in the Tyrrhenian Sea at $2000 \mathrm{~m}$ w.d. for almost seven months during 2000-2001. The results are still being evaluated and will be discussed in future papers.

\section{GEOSTAR System Description}

A detailed description of the GEOSTAR system is available in recent literature (e.g., Beranzoli et al., 1998, 2000; Favali et al., 2002; Gasparoni et al., 2002, Marvaldi et al., 2002). Only a schematic description of the system is given here.

GEOSTAR is based on a two-module scheme like the space shuttle: the Bottom Station (BS) or actual observatory, and the Mobile Docker (MD) devoted to deployment and recovery of the BS (Fig. 1).

The BS is a four-leg frame hosting the monitoring system including lithium batteries as power supply for sensors and devices, electronics mounted inside titanium vessels, hard disks for data storage, communication systems and scientific and status sensors (Gasparoni et al., 1998). The intelligent unit driving and controlling the BS is the Data Acquisition and Control System (DACS) (Fig. 2). It can activate the sensors and devices, driving the data flow toward hard disks and communication systems and eventually switch off sensors or stop data acquisition when events like water in- 
Table 1. Size and weight of GEOSTAR BS fully equipped.

\begin{tabular}{cl}
\hline Dimensions & base $3500 \times 3500$ (overall), height $2900 \mathrm{~mm}$ \\
Weight in air & $2160 \mathrm{~kg}$ (GEOSTAR 1 version)* \\
& $2942 \mathrm{~kg}$ (GEOSTAR 2 version) \\
& $1055 \mathrm{~kg}$ (GEOSTAR 1 version) \\
Weight in water & $1416 \mathrm{~kg}$ (GEOSTAR 2 version) \\
& Aluminum 5083 (frame), Titanium grade 5 (vessels), \\
Material & Stainless steel (docking pin) \\
& $4000 \mathrm{~m}$ \\
\hline
\end{tabular}

*: Reference to different versions of the GEOSTAR prototype relates to the enhancements introduced in the 2 nd phase of the project with respect to the 1 st phase.

Table 2. Sampling rates and accuracy of the GEOSTAR sensors.

\begin{tabular}{lccc}
\hline Sensor & Channels & Sampling rate & Accuracy \\
\hline 3-axes broad-band seismometer & 3 & 20 sample $/ \mathrm{s}$ & $* *$ \\
2-axes magnetometer & 2 & $1.25 \mathrm{sample} / \mathrm{s}$ & $* *$ \\
Scalar magnetometer & 1 & $1 \mathrm{sample} / 60 \mathrm{~s}$ & $* *$ \\
ADCP & 1 & 1 profile $/ 3600 \mathrm{~s}^{*}$ & $1 \mathrm{~cm} / \mathrm{s}$ \\
CTD & 1 & 1 sample $/ 3600 \mathrm{~s}$ & Conduct.: \\
& & & $0.001 \mathrm{~S} / \mathrm{m}$ \\
& & & T: $0.01^{\circ} \mathrm{C}$ \\
Light-transmissometer & 1 & 1 sample $/ 3600 \mathrm{~s}$ & $0.3 \%$
\end{tabular}

*: The ADCP profile consists of 50 samples at different water depth spacing about $0.8 \mathrm{~m}$ for a total of $50 \mathrm{~m}$ thick layer; **: Not applicable because of the non repeatability of the measurements.

trusion or anomalous elevation of temperatures in electronics vessels endanger BS components. The acquired data are uniquely time referenced by the high-precision clock in the seismometer package.

The MD, a simplified ROV, is managed from a ship through a dedicated opto-electro-mechanical cable and is equipped with a latch/release device mounted on a cone shaped frame, video cameras for seabed visual inspection and a compass to orient the BS. The MD can be moved horizontally by thrusters (Gerber and Schulze, 1998) especially useful in approaching the BS during recovery. The enhanced MD for deep-sea missions includes four more thrusters to increase the horizontal (two thrusters) and vertical (another additional two) movements, a transponder and an altimeter to check from the sea surface the MD location at depth, and a sonar to identify the BS location during recovery.

The primary Communication System (CS) is mounted on the BS and consists of buoyant capsules for data storage: the Messengers (MES) (Marvaldi et al., 1998). Two types of MES are used in GEOSTAR: Expendable (MES-E) and Storage (MES-S). The MES-E, with a storage capacity of 32 Kbytes, are automatically released by the BS when full of data or under particular conditions like sensor failure and contain daily summaries of scientific instruments, measurement statistics and status sensor data. The MES-S have a higher storage capacity, 40 Mbytes, and store scientific sensor data streams. The MES-S can be released by BS upon the operator's request through an acoustic command from the sea surface. Upon reaching the surface, the MES-S is located by the ARGOS satellite network to allow recovery. Meanwhile, the MES-E automatically starts transmitting summaries via satellite. An additional communication device based on a standard bi-directional Acoustic Telemetry System is mounted on the BS as a useful redundancy. The deep-sea CS developed in the GEOSTAR-2 project was enriched with a surface buoy for near real-time communication between the BS and onshore sites through an acousticsatellite and radio links. Table 1 shows the main GEOSTAR characteristics.

\subsection{Demonstration mission}

The GEOSTAR prototype was deployed on August 13th 1998 on the seafloor of the Adriatic Sea (Northern Italy) in $42 \mathrm{~m}$ w.d., about $50 \mathrm{~km}$ east of the Ravenna harbor and recovered after 21 days. The deployment and recovery operations were performed by means of the R/V Urania, managed by Italian National Research Council (CNR). The selection of the mission site was based both on the knowledge of geological-geotechnical soil characteristics (flat and consolidated seafloor, distance from turbulence source, absence of pockmarks and gassy sediments; Curzi and Veggiani, 1985; Mazzotti et al., 1987; Trincardi et al., 1994; Correggiari et al., 1996a, b) and safety factors (shallow water depth, vicinity to harbor logistics).

The mission configuration of the BS comprises a 3-axial broad-band seismometer, biaxial and scalar magnetometers, an Acoustic Doppler Current Profiler (ADCP), a Conductivity Temperature and Depth sensor (CTD) and a lighttransmissometer. The sampling rate and accuracy of the sen- 


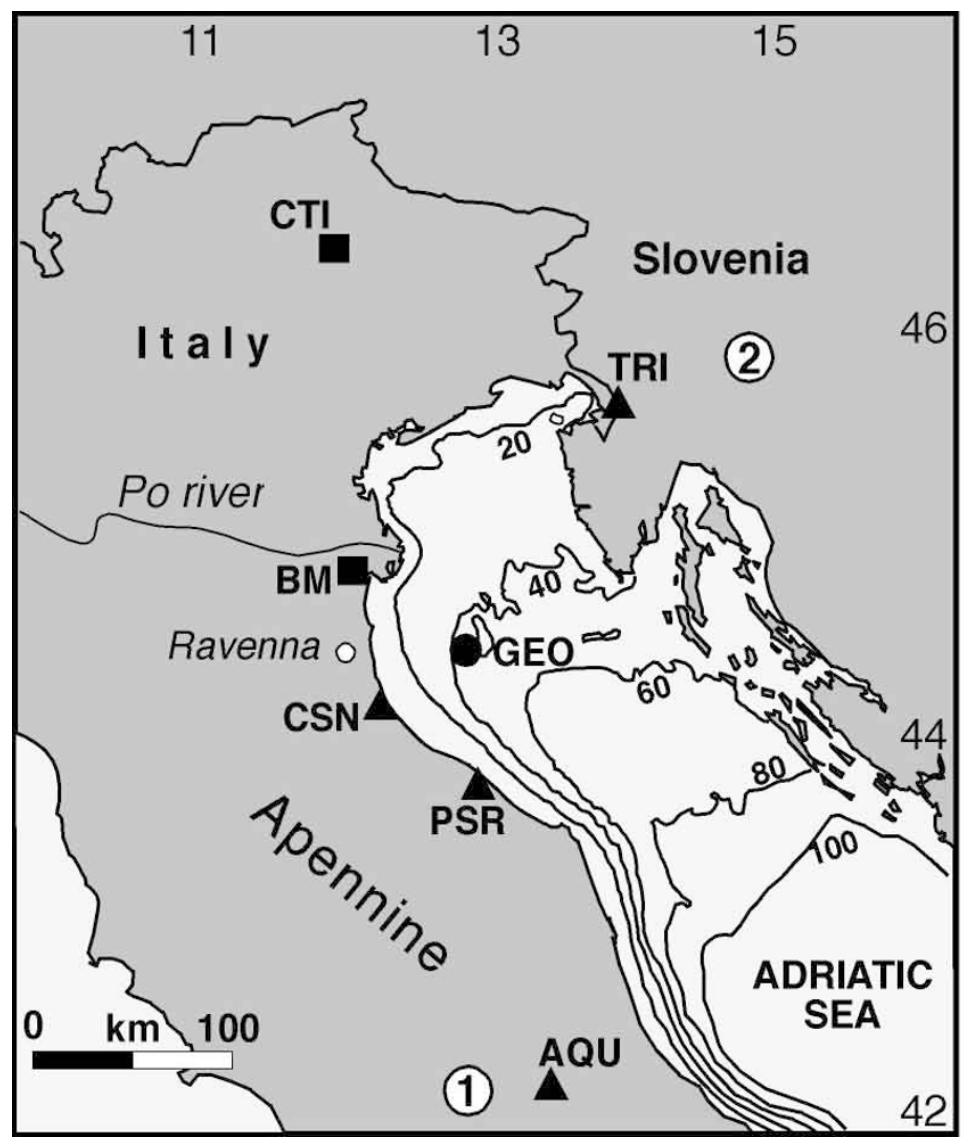

Fig. 3. Location of the sensors involved in the GEOSTAR experiment: the GEOSTAR observatory (GEO) is marked with a full dot; on-shore seismic stations are marked with full triangles; full squares represent the permanent magnetic station of Castello Tesino (CTI) and the temporary magnetic station of Bosco Mesola (BM). The numbers 1 and 2 are the location of the earthquakes examined in this paper (see Section 3.3 and Figs. 9, 10 and 11).

sor package are given in Table 2. The sensors were selected and developed to maintain a power consumption lower than $350 \mathrm{~mA}$ at $24 \mathrm{~V}$. Special care was taken in selecting the electronic components of the bi-axial magnetometer, completely developed by INGV. To reduce disturbance of the BS frame and electronics, devices were designed and implemented to install the seismometer and magnetometers. The former, already enclosed in a benthosphere, was then installed within a cylindrical heavy housing. To guarantee a good coupling with the sea bottom, it was released after touch-down and kept linked to the BS by a slack rope. The magnetometers were installed at the extremity of two booms attached on opposite vertices of the BS frame to keep them as far as possible from electronic noise sources. The booms, kept vertical during the deployment descent, were extended upon command once the BS settled on the seafloor.

After the BS touch-down, all sensor packages and devices were switched on through MD telemetry and their correct functioning was checked. Later on, the BS was definitively released by the MD and left on the sea bottom. Around 346 Mbytes of data, stored in the BS hard disks, were acquired over roughly 440 operational hours, corresponding to $97.8 \%$ of the mission's duration ( $\sim 40$ hours $)$. One MES-S was released upon acoustic command by an operator on board the $\mathrm{R} / \mathrm{V}$ Urania just before the recovery operations. The recovery was completed within 2 hours after the MD approached the BS.
During the sea mission, temporary magnetic and seismological stations were also installed on land as a reference for GEOSTAR's measurements. Figure 3 reports the locations of the mission site and of the on-land stations. Temporary seismological stations were installed close to the Adriatic coast, namely Pesaro (PSR) and Cesena (CSN). Data from the permanent broad-band seismological stations of Trieste (TRI) and L'Aquila (AQU), included in the MEDNET (Boschi et al., 1991), were also used. The reference station for the magnetic measures (full squares on Fig. 3) was the permanent one of Castello Tesino (CTI), in the National Magnetic Network which INGV manages, and the temporary one at Bosco Mesola (BM).

\section{Data Analysis \\ 3.1 Oceanographic data}

Measurements from the BS of pressure, temperature, conductivity and turbidity time series (1 sample/hour) are plotted in Figure 4. Data on temperature and salinity (the latter derived from conductivity), at the mission's beginning and end, were compared to the CTD profiles handled onboard (Fig. 5).

CTD pressure data from the BS clearly show tidal oscillations, and temperature data point out an overall positive trend. The ship-handled CTD reveals a significant pycnocline on the mission's first day (Julian day Jd-225) and a sharper, much deeper, pycnocline on its last (Jd-244). The evolution from the former stratification to the latter can be 

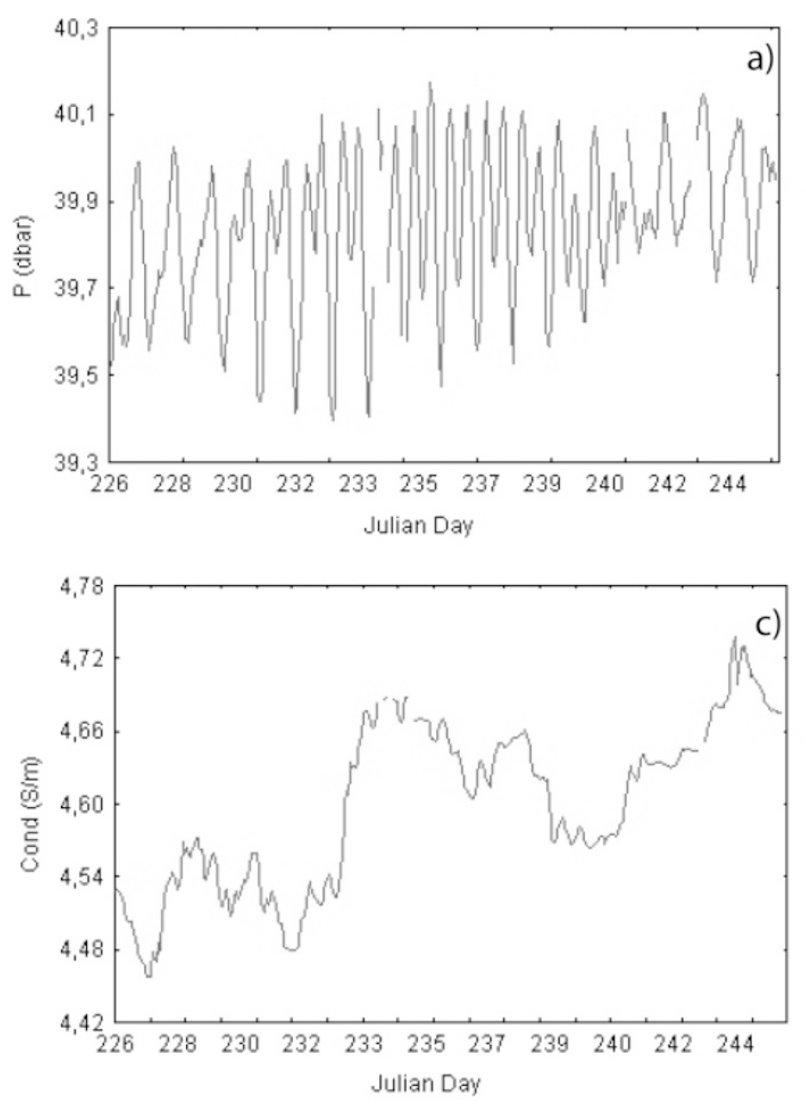
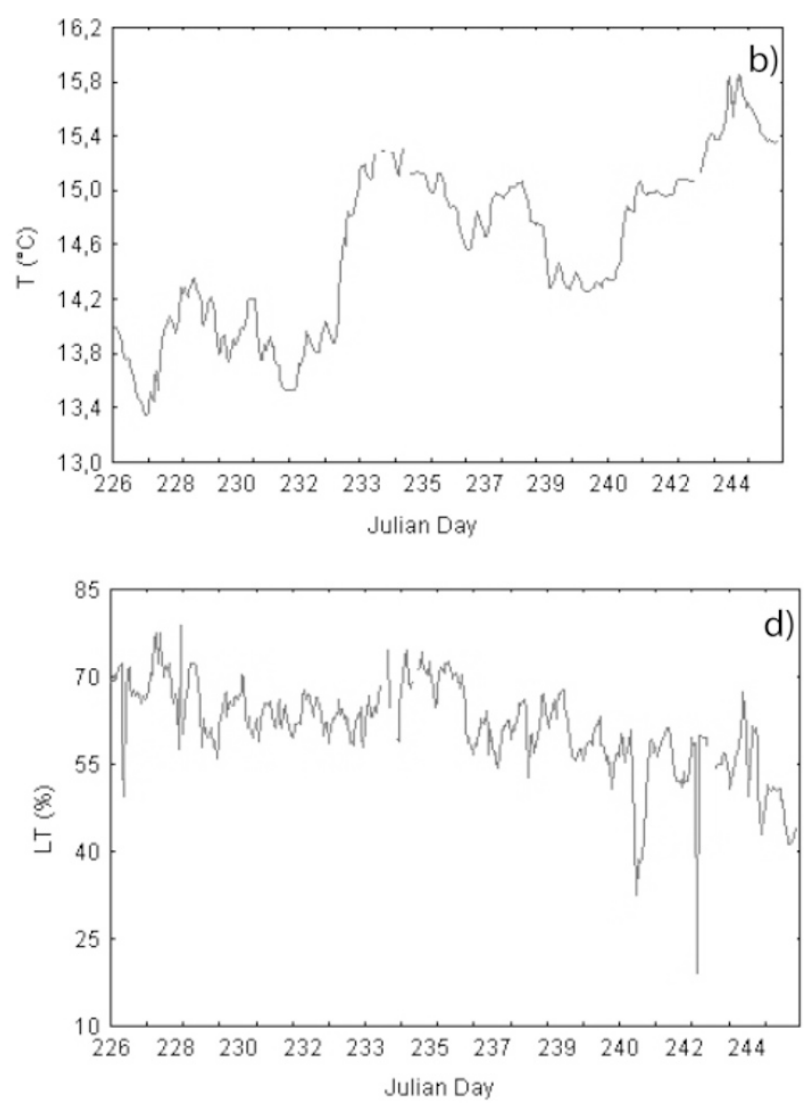

Fig. 4. CTD and transmissometer data: (a) pressure (P), (b) temperature (T), (c) conductivity (Cond) and (d) light transmissivity (LT). Time is in Julian days (13th August 1998 is Jd-228).

depicted with the ADCP data. The two CTD sensors were calibrated before and after the mission, and coherence in the temperature datasets explains their accuracy. This is not the case for the GEOSTAR conductivity data, which show an anomalous drift, most likely from sedimentation and suspended particles inside the conductivity cell.

A basic parameter used in studying the pycnocline with the ADCP is the shear magnitude $S=$ $\sqrt{\left[(d U / d z)^{2}+(d V / d z)^{2}\right]}$ where $U$ and $V$ are the current horizontal components and $z$ is the vertical. Figure 6 displays $S$ versus bin versus time, computed from the hourly currents measured $80 \mathrm{~cm}$ apart at 50 points ("bins" hereafter). Bin 1 is $\sim 4.4 \mathrm{~m}$ above the bottom and bin 42 (the uppermost bin not disturbed by the echo from the sea surface) $\sim 4 \mathrm{~m}$ below the surface. When comparing the stratification (Fig. 5) and the shear magnitude (Fig. 6), it is clear that the pycnocline is associated with large shear values, a well-known feature which separates the upper, lighter water and the lower, heavier water. It thus appears that the pycnocline markedly downwelled on Jd-240 from a few meters below the surface to near the sea bottom. Consequently, GEOSTAR was below the seasonal pycnocline in the deep layer before $\mathrm{Jd}-240$, and at the bottom of the surface layer after that. During this downwelling, the light transmission decreased by $\sim 32 \%$ (Fig. 4). Probably this was due to: the increased current intensity resuspending more sediments, the turbulence generated by the $\mathrm{BS}$, and the accumulated particles at all pycnocline levels. The highest values of downwards velocity $(\sim 20 \mathrm{~mm} / \mathrm{s}$, not shown) were also recorded.
Analysis of the oceanographic data shows a consistent deepening of the pycnocline. Although meteorological data at the scale of our study are not available, we hypothesize that a known change of meteorological conditions, beginning on Jd-240, could be the cause of the down-welling phenomenon.

\subsection{Geomagnetic data}

GEOSTAR BS was equipped with two magnetometers: a scalar Overhauser proton magnetometer by GEM System, and a suspended two-component magnetometer. The former, originally a GSM-19L, was properly adapted by GEM to work in deep water conditions. It measures the total intensity of the geomagnetic field. The biaxial magnetometer, based on a ring core fluxgate, allows acquisition of the horizontal (X-Y) components of the field by using the non-linear characteristics of ferromagnetic material. In principle, for ideal situations with perfect verticality and no drift of fluxgate sensors, the horizontal magnetometer combined with the scalar magnetometer would provide complete knowledge of the Earth's magnetic field vector. In practice, this is almost accomplished, although with some uncertainty, because no significant drift is expected during the short mission's duration, and the mechanical suspension, with a leveling compensation of \pm 15 degree, guarantees optimal verticality of the equipment as a whole.

The magnetic part of the experiment had two goals:

- to check the functioning of both magnetometers and assess the quality of their data; 


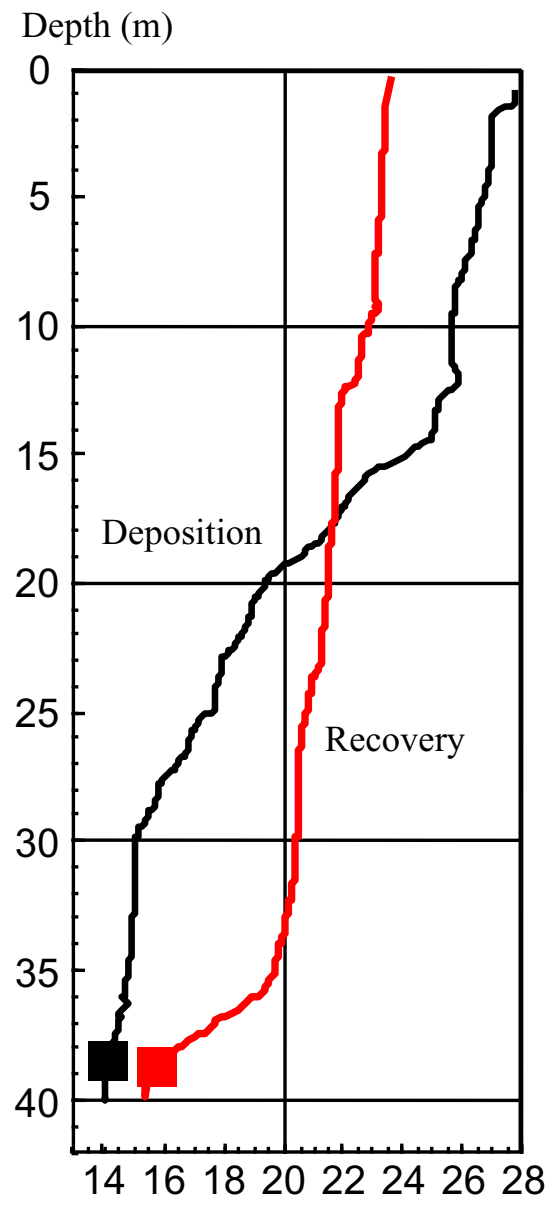

Temperature $\left({ }^{\circ} \mathrm{C}\right)$

\section{Depth (m)}

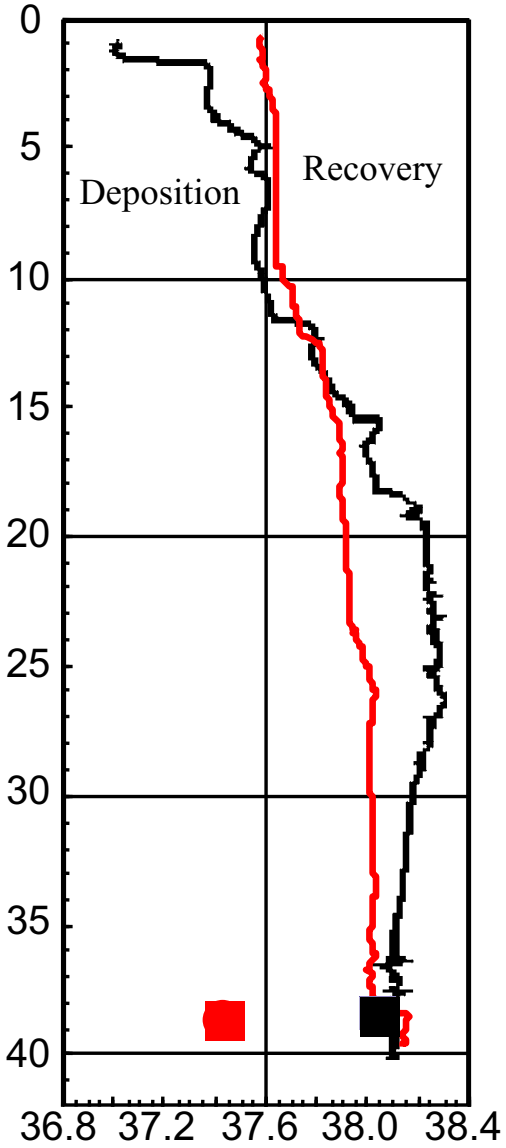

Salinity (PSU)

Fig. 5. Comparison between temperature and salinity data from the R/V Urania CTD casts (lines) and GEOSTAR CTD (squares) during the deposition (black, Jd-225) and the recovery (red, Jd-244).
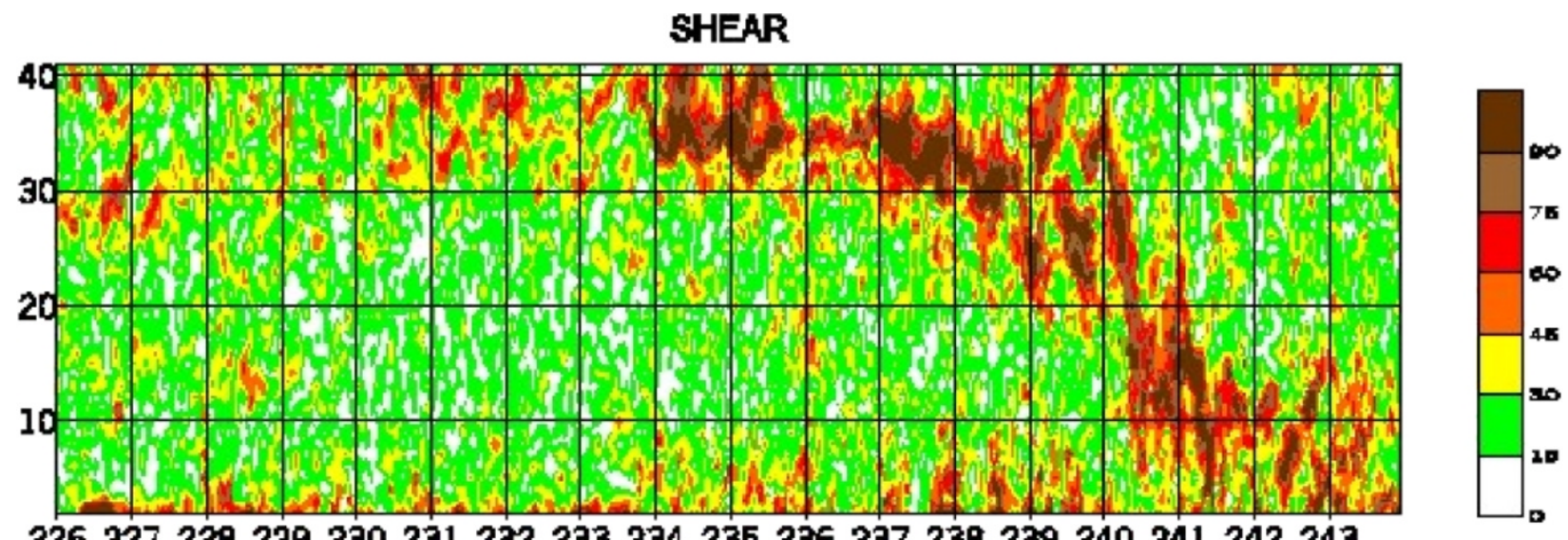

226227228229230231232233234235236297238239240241242243

Fig. 6. Shear magnitude $S$ in $\left(\mathrm{mm} \cdot \mathrm{s}^{-1}\right) \cdot \mathrm{m}^{-1}$ variation with time computed from the water velocity components measured by ADCP. On the y-axis the bins are reported from the top of the GEOSTAR observatory to few meters below the sea surface. The down welling of the pycnocline in the last days of the monitoring is evidenced by the progressive migration toward deeper layers of the dark and light brown.

- to assess the potential of the magnetic measurements for reliably orienting the station.

De Santis et al. (1999) have reported some preliminary results on the first goal. They compared the magnetic data with those from the ground reference station of BM and the CTI Observatory (see Fig. 3). Appropriate calibration of the $\mathrm{BM}$ data was possible after periodic visits to a nearby and permanent reference station, part of the National Magnetic 


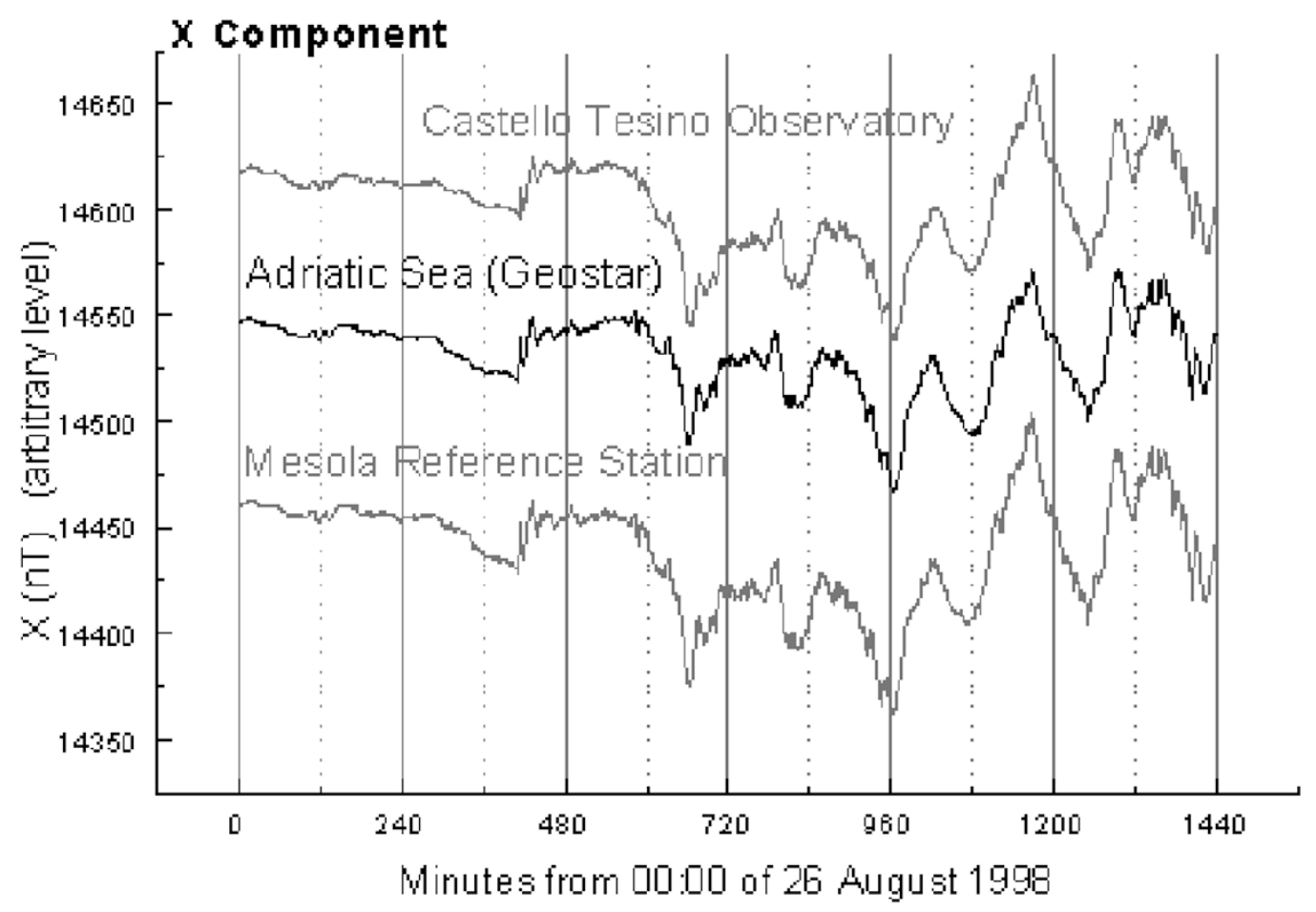

Fig. 7. Scalar magnetometer data of GEOSTAR (middle curve) in comparison with CTI (top curve) and BM data (bottom curve) recorded on a perturbed day (August 26).

Table 3. Seismological stations used in the GEOSTAR experiment.

\begin{tabular}{cccccr}
\hline Station & $\begin{array}{c}\text { Sensor } \\
\text { model }\end{array}$ & $\begin{array}{c}\text { Sensitivity } \\
{[\mathrm{bit} /(\mathrm{m} / \mathrm{s})]}\end{array}$ & Lat. & Lon. & $\begin{array}{r}\text { Alt. } \\
{[\mathrm{m}]}\end{array}$ \\
\hline $\mathrm{GEO}$ & $\mathrm{CMG}-1$ & $8.071 \mathrm{E}+09$ & $44.539 \mathrm{~N}$ & $12.871 \mathrm{E}$ & -42 \\
$\mathrm{CSN}^{(T)}$ & $\mathrm{CMG} 40$ & $4.195 \mathrm{E}+08$ & $44.201 \mathrm{~N}$ & $12.354 \mathrm{E}$ & 5 \\
$\mathrm{PSR}^{(T)}$ & $\mathrm{CMG} 40$ & $4.195 \mathrm{E}+08$ & $43.912 \mathrm{~N}$ & $12.884 \mathrm{E}$ & 50 \\
$\mathrm{AQU}^{(P)}$ & STS-1 & $1.043 \mathrm{E}+09$ & $42.354 \mathrm{~N}$ & $13.405 \mathrm{E}$ & 710 \\
$\mathrm{TRI}^{(P)}$ & $\mathrm{STS}-1$ & $1.043 \mathrm{E}+09$ & $45.66 \mathrm{~N}$ & $13.79 \mathrm{E}$ & 92 \\
\hline
\end{tabular}

${ }^{(P)}$ Permanent, ${ }^{(T)}$ Temporary.

Network used for absolute geomagnetic measurements.

The magnetic activity during the mission was varied and mixed. In particular, a magnetically quiet day (17 August 1998) and a perturbed one (26 August 1998) allowed us to check magnetometer data quality. Figure 7 shows the recordings of the scalar device on the disturbed day compared with the ground data. Our comparison of magnetic data confirmed that both scalar and two-axis magnetometers worked properly throughout.

The biaxial magnetometer on GEOSTAR allowed us in principle to reliably estimate station orientation as long as we knew the geomagnetic declination. A specific calibration procedure performed in a magnetically quiet site showed that GEOSTARS's frame and all installed instruments had negligible effect. Under such conditions, one can treat the mean daily declination in the CTI magnetic observatory $(300 \mathrm{~km}$ from the Adriatic Sea site) as equal to that of our biaxial magnetometer. Any difference in the horizontal components can be ascribed to the actual orientation of the GEOSTAR system with respect to the correct reference frame given by the CTI observatory. With a series of least squares regressions between daily horizontal components of magnetic GEOSTAR data and corresponding components at the CTI observatory, we estimated a clockwise orientation in the BS of about $20^{\circ}$ with respect to true North.

\subsection{Seismic data}

GEOSTAR's broad-band seismometer is a threecomponent Guralp CMG-1T. The corner period of the CMG-1 broad-band sensor is $\mathrm{T}_{\mathrm{CMG} 1}=360 \mathrm{~s}$ and in the flat part of the transfer function $(0.003-50 \mathrm{~Hz})$, the seismic signals are magnified by a factor of $\mathrm{G}_{\mathrm{CMG} 1}=6400 \mathrm{~V} \cdot \mathrm{s} / \mathrm{m}$. A 24 bit digitizer (type Guralp DM24; sensitivity $1.24 \times 10^{6}$ counts/V) samples the seismic data at $20 \mathrm{~Hz}$.

The seismometer worked continuously for the duration of the Adriatic experiment. Absolute timing was checked both before and after the mission, giving an expected time drift less than $2 \times 10^{-3}$ s per sample. To evaluate the quality of the seismic data recorded by the GEOSTAR seismometer 

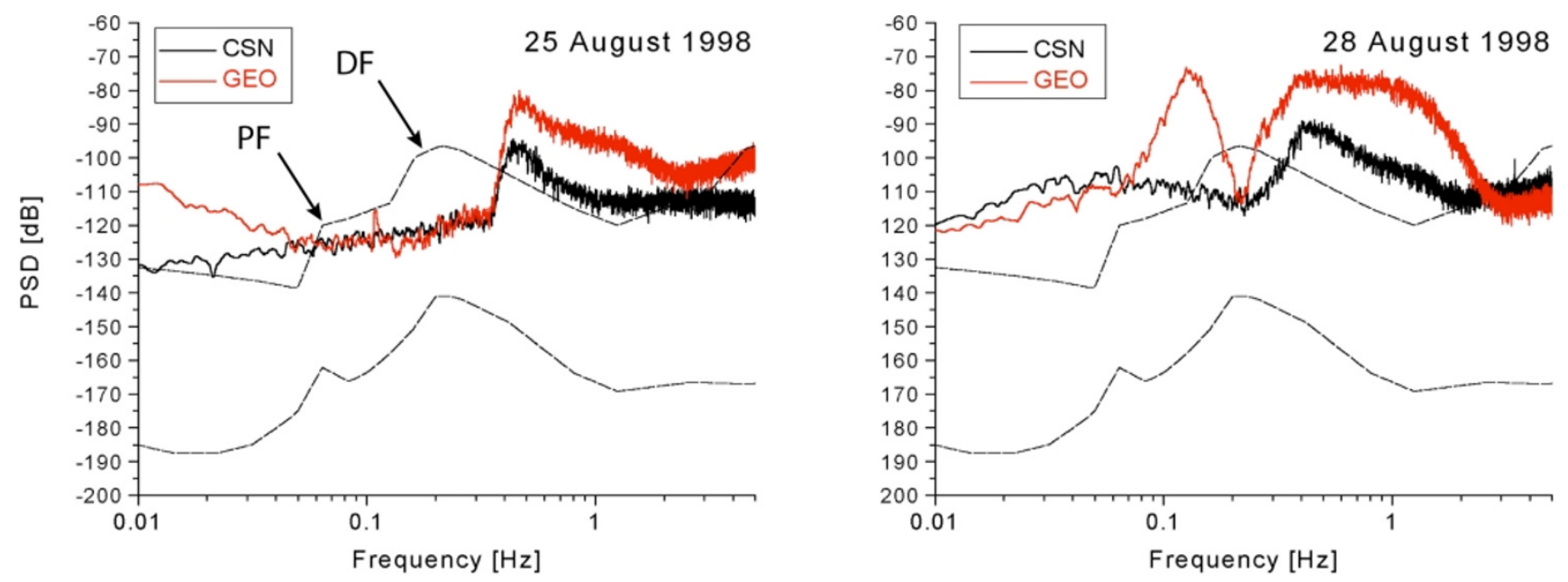

Fig. 8. Seismic noise at the GEOSTAR observatory (GEO) compared with CSN land station: vertical component of the power spectral density (PSD) in acceleration during a low sea-state day (August 25, left) and a high sea-state day (August 28, right). The dashed lines are the High Noise Model (upper line) and the Low Noise Model (lower line) according to Peterson (1993). The Primary Frequency (PF) and the Double Frequency (DF) peaks are also reported.

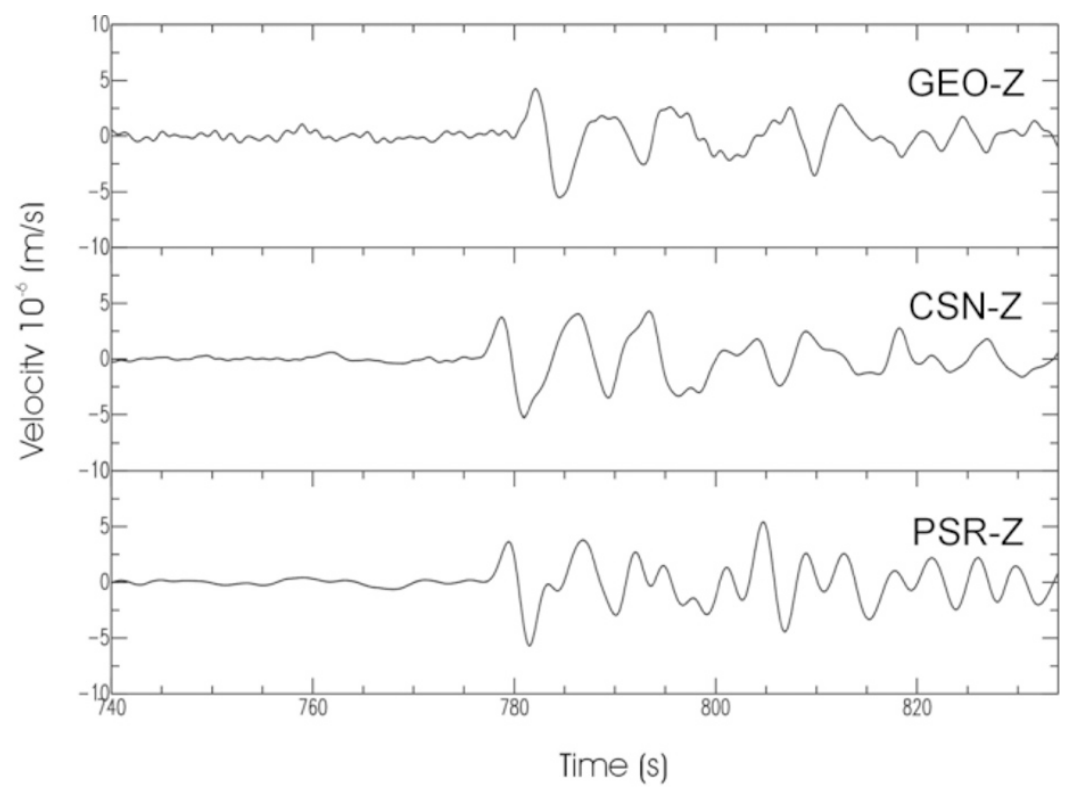

Fig. 9. Z-component of a teleseismic earthquake occurred in Aleutian Islands on August 20, 15:00:08 GMT, recorded by GEO (top), CSN (middle) and PSR (bottom).

(GEO), we analyzed seismic noise and earthquake recordings through comparison with on-land data from permanent and temporary seismological stations. The features of those stations (see Fig. 3) are reported in Table 3.

PSR was installed on bedrock at about $60 \mathrm{~km}$ south of GEO and CSN, closer to GEO, was installed in a coastal area on the same geological complex as GEO: alluvial deposits of the Po river delta.

The seismic noise study was based on the analysis of Power Spectral Density (PSD) computed for the mission period and compared to Peterson's (1993) New Low/High Noise Model (NLNM, NHNM). The PSD of the vertical components of GEO and CSN are plotted in Fig. 8 (left) and (right) as resulting from the over six segments, each averaging over 1-hour, taken on August 25th and 28th. The first day represented a good sea-state and the second a bad.
After comparing the spectral position of the Primary Frequency (PF) of the marine microseisms and Double Frequency (DF) peak of GEO and CSN PSD (Darbyshire and Okeke, 1969) with NLNM and NHNM, we observed a significant shift to higher frequencies. This feature is usually observed on recordings of the Trieste broad-band seismological station (TRI) part of MEDNET. The high-noise level of the GEO and CSN DF can be explained by the nearby Adriatic basin, as has been observed at the GEOSCOPE broadband island stations (Stutzmann et al., 2000). This effect reflects the sensitivity of those stations to ocean storms. Noticeably, the Adriatic Sea is an almost-enclosed and shallow basin whose average depth is $150 \mathrm{~m}$ North of $\sim$ Lat. $42^{\circ} \mathrm{N}$; the marine waves responsible for microseisms in these cases exceed ocean waves in frequency (Mosetti, 1964).

In Fig. 8 (left) (favorable sea-state), the value of $0.3 \mathrm{~Hz}$ 

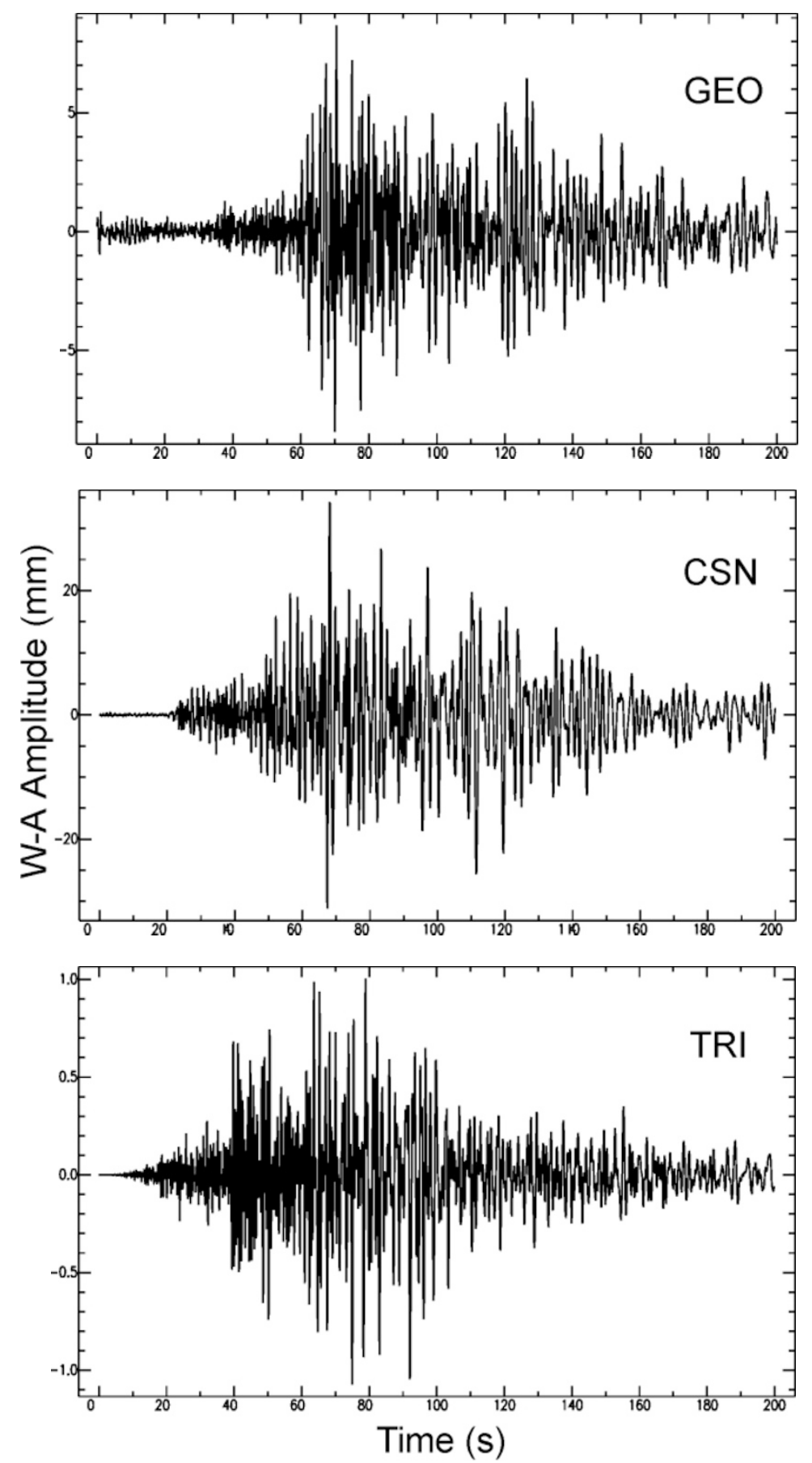

Fig. 10. E-W component of Wood-Anderson seismograms of the Central Italy earthquake (August 15, number 1 in Fig. 3) obtained from GEO, CSN and TRI. The time axis in not the absolute time but is related to the portion of signal selected.

roughly separates, low and high frequency ranges, in which the noise level is lower and higher than NHNM, respectively. The abruptly increased noise level at frequencies higher than $0.3 \mathrm{~Hz}$ for both CSN and GEO, and the overall similarities of the GEO and CSN noise curves, support the hypothesis of a shared site effect, since both stations were located on alluvial deposits of the Po River. The PSD of GEO and CSN computed for August 28th (high sea-state, Fig. 8 (right)), clearly shows the PF of the marine microseisms of GEO noise to be $0.11 \mathrm{~Hz}$. But the DF peak of GEO noise is hidden by the increased noise level at frequencies higher than $0.4 \mathrm{~Hz}$. Similar noise changes for CSN, although more modest, sug- gest that wave motion shakes the shallow-depth sea bottom at the GEOSTAR's BS site. Note that the well known notch separating PF and DF peaks is not clearly visible on days of low sea-state either on GEO or CSN PSD. The notch only becomes clear during bad sea days (see Fig. 8 (right)) separating the PF and DF peaks. However, it reaches the same noise values at corresponding frequencies during low seastate days.

To evaluate the ground coupling of the GEO-deployment, we analyzed teleseismic (Fig. 9) and regional events (Figs. 10 and 11) and compared them to recordings from onland, temporary reference stations. The hypocentral param- 

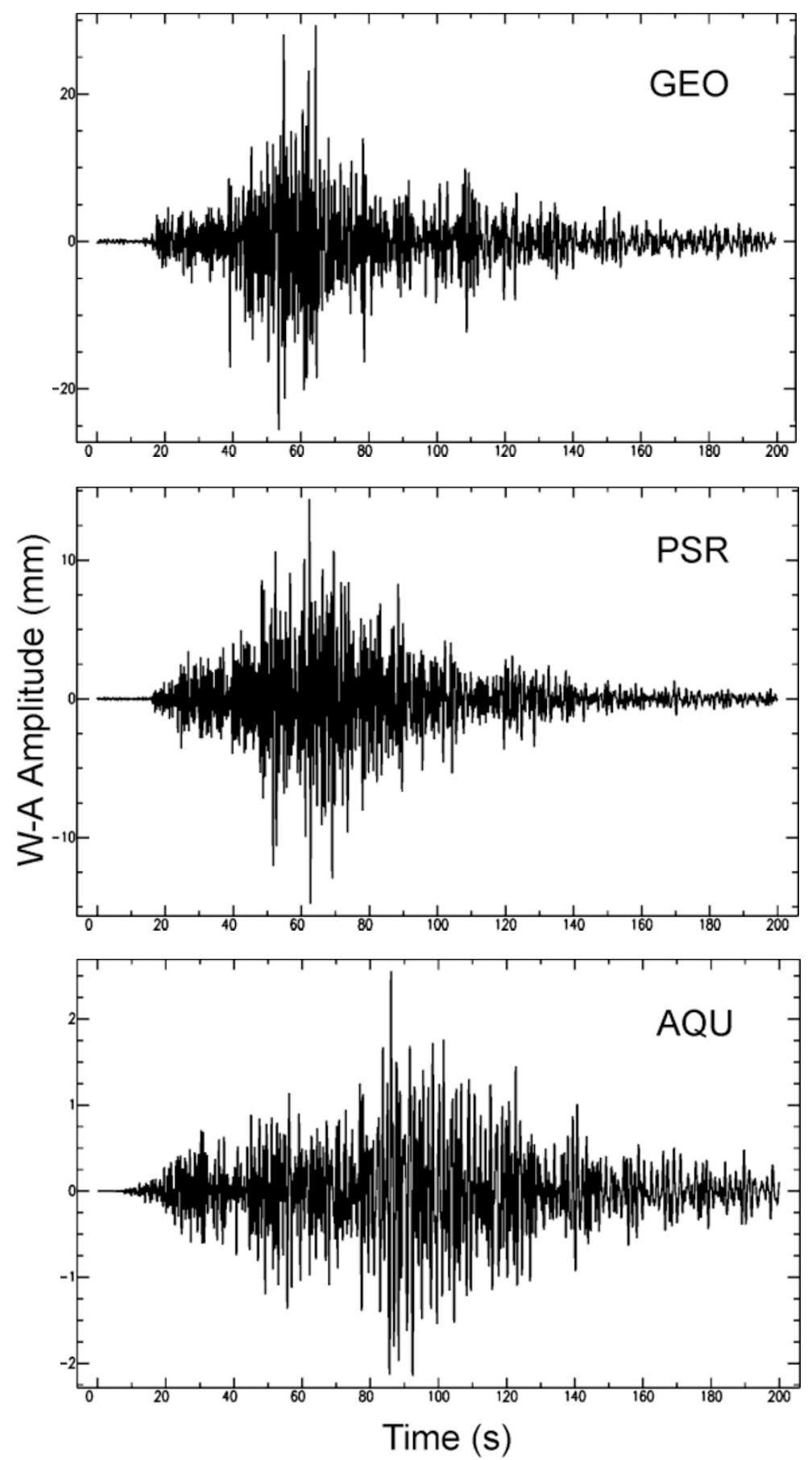

Fig. 11. N-S component of Wood-Anderson seismograms of the Slovenia earthquake (August 31, number 2 in Fig. 3) obtained for GEO (top), PSR, and AQU. The time axis in not the absolute time but is related to the portion of signal selected.

eters of major earthquakes during the experiment are summarized in Table 4. Figure 9 shows the P-wave arrival of the Aleutian earthquake recorded by GEO, CSN and PSR: absolute amplitudes reach the same values $(\sim 5 \mu \mathrm{m} / \mathrm{s})$. Similarities between the amplitude and shape of the recordings indicate that the coupling of our sensor GEO with the ground compares well with standard on-shore installation.

Note that PSD values at GEO station for frequencies higher than $0.3 \mathrm{~Hz}$, exceeding NHNM, may limit the detection of hypocenters very close to the BS. As shown in Fig. 8 the threshold is roughly estimated around magnitude 3 .

The local magnitude $M_{L}(\Delta<600 \mathrm{~km})$ was determined for two regional events which occurred in Central Italy and Slovenia, using the recordings of GEO, CSN, PSR, AQU and TRI stations. According to Richter's definition, the local magnitude $M_{L}$ is calculated from the average of the maximum amplitudes of the two horizontal components measured in $\mathrm{mm}$ on a Wood-Anderson (WA) seismograph. Therefore the usual practice of deriving $M_{L}$ from other kinds of seismic instruments requires that seismograms from those instruments be converted to equivalent WA amplitudes by spectral division or point-by-point amplitude conversion. Basically this consists in removing the response of the broadband sensor, followed by a simulation of a WA displacement sensor. 
Table 4. Earthquakes recorded by GEOSTAR.

\begin{tabular}{cccccc}
\hline \multicolumn{1}{c}{ Date } & $\begin{array}{c}\text { Time } \\
\text { (hh:min sec) }\end{array}$ & Lat. & Lon. & Mag. & $\begin{array}{c}\text { Epicenter } \\
\text { location }\end{array}$ \\
\hline 1998, Aug. 15 & $05: 18$ '09 & $42.41 \mathrm{~N}$ & $12.96 \mathrm{E}$ & $4.6 M_{L}$ & Central Italy \\
1998, Aug. 20 & $15: 00$ '08 & $51.62 \mathrm{~N}$ & $175.27 \mathrm{~W}$ & $5.6 m_{b}$ & Aleutian Islands \\
1998, Aug. 27 & $09: 03$ '36 & $39.65 \mathrm{~N}$ & $77.35 \mathrm{E}$ & $5.6 m_{b}$ & China \\
1998, Aug. 31 & $02: 32$ '04 & $45.93 \mathrm{~N}$ & $14.77 \mathrm{E}$ & $4.9 M_{L}$ & Slovenia \\
\hline
\end{tabular}

Table 5. Comparison of $M_{L}$ for two regional events.

\begin{tabular}{llccccc}
\hline Event & & GEO & CSN & PSR & AQU & TRI \\
\hline \multirow{3}{*}{ Central Italy } & $M_{L}$ & 4.6 & 4.7 & 4.6 & 4.6 & 4.4 \\
& Back azimuth & $178^{\circ}$ & $166^{\circ}$ & $178^{\circ}$ & $285^{\circ}$ & $188^{\circ}$ \\
& Distance $(\mathrm{km})$ & 234 & 201 & 163 & 38 & 380 \\
Slovenia & $M_{L}$ & 5.0 & 4.9 & 5.1 & 4.8 & - \\
& Back azimuth & $43^{\circ}$ & $44^{\circ}$ & $33^{\circ}$ & $16^{\circ}$ & - \\
\hline
\end{tabular}

—: TRI was not operating during the Slovenia event.

The natural periods of GEO and of the temporary and permanent on-land broad-band stations exceed the WA natural period. Thus, the whole simulation process can be simplified by convoluting the recorded seismograms with the WA impulse response.

Before computing the Richter magnitude from GEO recordings, we rotated the horizontal seismometer components as the GEOSTAR magnetic measurements revealed that the BS was not exactly pointed to the North.

Figure 10 shows the E-W component of the WA seismograms of GEO, CSN and TRI for the event in Central Italy. Figure 11 depicts the N-S component of the WA seismograms of GEO, PSR and AQU for the earthquake occurred in Slovenia.

Table 5 lists the calculated $M_{L}$-value for the two earthquakes together with their epicentral distances and the backazimuths. The $M_{L}$ values determined by GEOSTAR seismometer recordings agree with those values obtained from the land-based stations, some of which (AQU and TRI) commonly used as references for such calculation.

\section{Conclusions}

The first GEOSTAR mission validated the system as a whole and the deployment/recovery procedure. Our analysis of oceanographic and geophysical data recorded during the mission demonstrates properly installed sensors and an overall quality of measurement comparable with standard on-shore instruments.

The relationship between water conductivity and temperature reveals two distinct periods (Jd 226.8-240.5 and Jd 240.5-245.4) having "different waters" with slightly different chemical and physical characteristics. The shear values computed from the ADCP data also clearly detect a pycnocline deepening on $240 \mathrm{Jd}$ in which warmer and lighter waters from the shallower layers replaced deep waters.

Our magnetometers operated optimally, as shown by com- parison with data from onshore stations during magnetically quiet and perturbed days. By comparing the declination measurements of GEOSTAR and the CTI permanent geomagnetic station, we computed an orientation of the BS of $\sim 20^{\circ}$ clockwise from North.

The shape and amplitude of teleseismic waveforms recorded by GEO are similar to on-shore recordings, demonstrating the sensor's satisfactory ground coupling. Noise spectra are also comparable with those from the nearby onland station sited similarly. $M_{L}$ computed for the GEOSTAR broad-band seismometer recordings of regional earthquakes during the mission agree with those obtained from on-land broad-band stations.

GEOSTAR has passed its first test. We find this multidisciplinary research platform highly suitable for oceanic monitoring.

Acknowledgments. The GEOSTAR Project was funded by the EC under the Marine Science and Technology Programme (contract n. MAS3-CT95-0007). Partners in the projects included INGV, Istituto per la Geologia Marina-CNR, Tecnomare S.p.A. (Italy); IFREMER, Laboratoire d'Océanographie et de Biochemie - CNRS, Orca Instrumentation (France), Technische Universität Berlin (Germany). The authors wish to thank the local technical project managers: Jean Marvaldi, Hans Gerber, Francesco Gasparoni, Jean-Michel Coudeville and Gerard Ayela. Thanks are also due to Captain Emanuele Gentile, Claudio Viezzoli and the crew of R/V Urania. Special gratitude is due to the enthusiastic Gilles Ollier, GEOSTAR EC scientific officer. We thank Mrs. Katleen J. Jackson for the English revision of the manuscript. We dedicate this work to our friend and colleague, Giuseppe Smriglio, who prematurely passed away in 2001 .

\section{References}

Austin, T. C., J. B. Edson, W. R. McGillis, M. Purcell, R. A. Petitt, M. K. McElroy, C. W. Grant, J. Ware, and S. K. Hurst, A network-based telemetry architecture developed for the Martha's vineyard coastal observatory, IEEE J. Ocean. Eng., 27, 228-234, 2002.

Beranzoli, L., A. De Santis, G. Etiope, P. Favali, F. Frugoni, G. Smriglio, F. Gasparoni, and A. Marigo, GEOSTAR: a GEophysical and Oceano- 
graphic STation for Abyssal Research, Phys. Earth Planet. Int., 108, 175183,1998

Beranzoli, L., T. Braun, M. Calcara, D. Calore, R. Campaci, J. M Coudeville, A. De Santis, G. Etiope, P. Favali, F. Frugoni, J-.L. Fuda F. Gamberi, F. Gasparoni, H. Gerber, M. Marani, J. Marvaldi, C. Millot, P. Palangio, G. Romeo, and G. Smriglio, European seafloor observatory offers new possibilities for deep-sea study, EOS, Trans., $A G U, \mathbf{8 1}(5), 45$ 49, 2000.

Berta, M., F. Gasparoni, and M. Capobianco, Abyssal Benthic Laboratory (ABEL): a novel approach for long-term investigation at abyssal depths, J. Mar. Syst., 6, 211-225, 1995.

Boschi, E., D. Giardini, and A. Morelli, MedNet-The broad-band seismic network for the Mediterranean, Nuovo Cimento, 14C, 79-99, 1991.

Butler, R., A. D. Chave, F. K. Duennebier, D. R. Yoerger, R. Petitt, D. Harris, F. B. Wooding, A. D. Bowen, J. Bailey, J. Jolly, E. Hobart, J. A Hildebrand, and H. Dodeman, Hawaii-2 Observatory pioneers opportunities for remote instrumentation in ocean studies, EOS Trans., $A G U, \mathbf{8 1}$, 157 and 162-163, 2000.

Campillo, M., N. Shapiro, A. Paul, and N. Bethoux, Data analysis from SISBALIG II OBS array in the Ligurian Sea, Proceedings of the International Workshop Multidisciplinary Observatories on the Deep Sea Floor, edited by J.-P. Montagner and Y. Lancelot, Marseille, France, 88, 1995.

Chave, A. D., F. K. Duennebier, R. Butler, J.-F. Petitt, Jr., F. B. Wooding, D. Harris, J. W. Bailey, E. Hobart, J. Jolly, A. D. Bowen, and D. R. Yoerger H2O: The Hawaii-2 Observatory, in Science-Technology Synergy for Research in Marine Environment: Challenges for the XXI Century, Development in Marine Technology, 12, edited by L. Beranzoli, P. Favali, and G. Smriglio, pp. 83-91, Elsevier, Amsterdam, 2002.

Correggiari, A., M. E. Field, and F. Trincardi, Late Quaternary Transgres sive Large Dunes on the Sediment Starved Adriatic Shelf, Geol. Soc. Spec. Publ., 117, pp. 155-169, 1996a.

Correggiari, A., M. Roveri, and F. Trincardi, Late Pleistocene and Holocene evolution of the North Adriatic Sea. Il Quaternario, 2, 697-704, 1996 b.

Curzi, P. V. and A. Veggiani, I pockmarks nel Mare Adriatico centrale, Acto Nat. Ateneo Parmense, 21, 79-90, 1985.

Darbyshire, J. and E. O. Okeke, A study of primary and secondary microseism recorded in Anglesey, Geophysics, 17, 63-92, 1969.

De Santis, A., D. Di Mauro, P. Favali, P. Palangio, G. Romeo, and G. Smriglio, GEOSTAR project: the performed seafloor mission in the Adriatic sea, Proceedings of MARELEC 99 Conference, Brest, France, 219-230, 1999.

Duennebier, F. K., HUGO: The Hawaii Undersea Geo-Observatory, Proceedings of the International Workshop Multidisciplinary Observatories on the Deep Sea Floor, Marseille, France, edited by J.-P. Montagner and Y. Lancelot, 105-108, 1995.

Duennebier, F. K., D. W. Harris, J. Jolly, J. Caplan-Auerbach, R. Jordan, D. Cpson, K. Stiffel, J. Babinec, and J. Bosel, HUGO: the Hawaii Undersea Geo-Observatory, IEEE J. Ocean. Eng., 27, 218-227, 2002.

Favali, P., G. Smriglio, L. Beranzoli, T. Braun, M. Calcara, G. D’Anna, A. De Santis, D. Di Mauro, G. Etiope, F. Frugoni, V. Iafolla, S. Monna, C. Montuori, S. Nozzoli, P. Palangio, and G. Romeo, Towards a permanent deep sea observatory: the GEOSTAR European experiment, in ScienceTechnology Synergy for Research in Marine Environment: Challenges for the XXI Century, Development in Marine Technology, 12, edited by L. Beranzoli, P. Favali, and G. Smriglio, pp. 111-120, Elsevier, Amsterdam, 2002.

Gasparoni, F., D. Calore, R. Campaci, and A. Marigo, GEOSTARdevelopment and test of an innovative benthic station for long-term observations at abyssal depths, Proceedings (on CD-ROM) of the IEEE Conference OCEANS '98, 1998.

Gasparoni, F., D. Calore, and R. Campaci, From ABEL to Geostar: development of the first European deep-sea scientific observatory, in ScienceTechnology Synergy for Research in Marine Environment: Challenges for the XXI Century, Development in Marine Technology, 12, edited by L. Beranzoli, P. Favali and G. Smriglio, pp. 143-159, Elsevier, Amsterdam, 2002.

Gerber, H. and D. Schulze, GEOSTAR - development and test of a deployment and recovery system for deep-sea benthic observatories, Proceedings (on CD-ROM) of the IEEE Conference OCEANS '98, 1998.

Kasahara, J. and H. Momma, VENUS (Versatile Eco-monitoring Network by Undersea-Cable System) project using TPC-2 (Okinawa-Guam) submarine cable, Proceedings of the International Workshop Multidisciplinary Observatories on the Deep Sea Floor, Marseille, France, edited by J.-P. Montagner and Y. Lancelot, 128, 1995.
Kasahara, J., H. Utada, and H. Kinoshita, GeO-TOC project-reuse of submarine cables for seismic and geoelectrical measurements, J. Phys Earth, 43, 619-628, 1995.

Kasahara, J., T. Sato, H. Momma, and Y. Shirasaki, A new approach to geophysical real-time measurements on a deep-sea floor using decommissioned submarine cables, Earth Planets Space, 50, 913-925, 1998

Kasahara, J., Y. Shirasaki, and H. Momma, Multidisciplinary geophysical measurement on the ocean floor using decommissioned submarine cables: VENUS Project, IEEE J. Ocean. Eng., 25, 111-120, 2000.

Marvaldi, J., J. Blandin, Ch. Podeur, J.-M. Coudeville, J. Antoine, D. Barbot, D. Fellmann, and D. Rhodes, GEOSTAR - development and test of a communication system for deep-sea benthic stations, Proceedings (on CD-ROM) of the IEEE Conference OCEANS '98, 1998.

Marvaldi, J., Y. Aoustin, G. Ayela, D. Barbot, J. Blandin, J.-M. Coudeville, D. Fellmann, G. Loaëc, C. Podeur, and A. Priou, Design and realisation of communication systems for the GEOSTAR project, in ScienceTechnology Synergy for Research in Marine Environment: Challenges for the XXI Century, Development in Marine Technology, 12, edited by L. Beranzoli, P. Favali, and G. Smriglio, pp. 161-181, Elsevier, Amsterdam, 2002.

Mazzotti, L., S. Segantini, M. Tramontana, and F. C. Wezel, Characteristics of pockmarks on the Jabuka Trough (Central Adriatic Sea), Boll. Ocean. Teor. Appl., 5, 237-250, 1987.

Momma, H., K. Mitsuzawa, Y. Kaiho, and H. Hotta, Long-term and Real Time observation on deep sea floor off Hatsushima Island in Sagami Bay, Proceedings of the International Workshop Multidisciplinary Observatories on the Deep Sea Floor, Marseille, France, edited by J.-P. Montagner and Y. Lancelot, 149, 1995.

Montagner, J.-P. and Y. Lancelot (eds.), Proceedings of International Workshop Multidisciplinary observatories on the deep seafloor, Marseille, France, 229, 1995.

Montagner, J.-P., J.-F. Karczewski, B. Romanowicz, S. Bouaricha, P. Lognonne, G. Roult, E. Stutzmann, J.-L. Thirot, J. Brion, B. Dole, D. Fouassier, J. C. Koenig, J. Savary, L. Floury, J. Dupond, A. Echardour, and H. Floc'h, The French Pilot Experiment OFM-SISMOBS: first scientific results on noise level and event detection, Phys. Earth Planet. Int., 84, 321-336, 1994a.

Montagner, J.-P., B. Romanowicz, and J.-F. Karczewski, A first step toward an Oceanic Geophysical Observatory, EOS Trans. AGU, 75, 150-151, 154, $1994 \mathrm{~b}$.

Mosetti, F., Oceanografia, Del Bianco Editore, Udine, 1964.

Peterson, J., Observations and modeling of seismic background noise, U.S.G.S. Open-File Report 93-322, Albuquerque, New Mexico, U.S.A., 1993.

Petitt, R. A., F. B. Wooding, D. Harris, J. W. Bailey, E. Hobart, J. Jolly, A. D. Chave, F. K. Duennebier, and R. Butler, The Hawaii-2 Observatory, IEEE J. Ocean. Eng., 27, 245-253, 2002.

Rigaud, V., D. Semac, M. Nokin, DESIBEL Team, G. Tietze, H. Hamann, V. Goetz, and A. Pascoal, New methods for Deep-Sea Intervention on future Benthic Laboratories, DESIBEL Project-Final Results, Comparison of concepts and at sea validation. Proceedings (on CD-ROM) of the IEEE Conference OCEANS '98, 1998.

Romanowicz, B., D. Stakes, J.-P. Montagner, P. Tarits, R. Uhrhammer, M. Begnaud, E. Stutzmann, M. Pasyanos, J.-F. Karczewski, S. Etchemendy, and D. Neuhauser, MOISE: A pilot experiment towards long-term seafloor geophysical observatories, Earth Planets Space, 50, 927-937, 1998.

Schofield, O., T. Bergmann, P. Bisset, J. F. Grassle, D. B. Haidvogel, J. Kohut, M. Moline, and S. M. Glenn, The Long-term Ecosystem Observatory: an integrated coastal observatory, IEEE J. Ocean. Eng., 27, 146154, 2002.

Stutzmann, E., G. Roult, and L. Astiz, GEOSCOPE station noise levels, Bull. Seism. Soc. Am., 90, 690-701, 2000.

Thiel, H., K. O. Kirstein, C. Luth, U. Luth, G. Luther, L. A. Meyer-Reil, O. Pfannkuche, and M. Weydert, Scientific requirements for an abyssal benthic laboratory, J. Mar. Syst., 4, 421-439, 1994.

Trincardi, F., A. Correggiari, and M. Roveri, Late Quaternary transgressive erosion and deposition in a modern epicontinental shelf: the Adriatic semienclosed basin, Geo-Mar. Lett., 14, 41-51, 1994.

L. Beranzoli (e-mail: beranzoli@ingv.it), T. Braun, M. Calcara, P. Casale, A. De Santis, G. D’Anna, D. Di Mauro, G. Etiope, P. Favali, J.L. Fuda, F. Frugoni, F. Gamberi, M. Marani, C. Millot, C. Montuori, and G. Smriglio 